(2)

\title{
Repeated adjacent segment diseases and fractures in osteoporotic patients: a case report
}

\author{
This article was published in the following Dove Press journal: \\ Therapeutics and Clinical Risk Management \\ 28 July 2016 \\ Number of times this article has been viewed
}

\author{
Hsin-Yao Chen' \\ Chiu-Liang Chen ${ }^{1,2}$ \\ Wei-Liang Chen ${ }^{3}$ \\ 'Department of Orthopedic \\ Surgery, Changhua Christian \\ Hospital, Changhua City, ${ }^{2}$ Liberal \\ Arts Center of Da Yeh University, \\ Dacun Township, Changhua County, \\ Taiwan; ${ }^{3}$ Department of Clinical \\ Image, Changhua Christian Hospital, \\ Changhua City, Changhua County, \\ Taiwan
}

\begin{abstract}
Background: Pedicle screw instrumentation for treating spinal disorder is becoming increasingly widespread. Many studies have advocated its use to facilitate rigid fixation for spine; however, adjacent segmental disease is a known complication. Instrumented fusion for osteoporotic spines remains a significant challenge for spine surgeons. Prophylactic vertebroplasty for adjacent vertebra has been reported to reduce the complications of junctional compression fractures but has raised a new problem of vertebral subluxation. This case report is a rare and an extreme example with many surgical complications caused by repeated instrumented fusion for osteoporotic spine in a single patient. This patient had various complications including adjacent segmental disease, vertebral subluxation, and junctional fractures on radiographs and magnetic resonance images.

Case presentation: An 81-year-old Taiwanese woman underwent decompression and instrumented fusion of L4-L5 in Taiwan 10 years ago. Due to degenerative spinal stenosis of L3-L4 and L2-L3, she had decompression with instrumented fusion from L5 to L1 at the previous hospital. However, catastrophic vertebral subluxations with severe neurologic compromise occurred, and she underwent salvage surgeries twice with prolonged instrumented fusion from L5 to T2. The surgeries did not resolve her problems of spinal instability and neurologic complications. Eventually, the patient remained with a Frankel Grade C spinal cord injury.

Conclusion: Adjacent segmental disease, junctional fracture, and vertebral subluxation are familiar complications following instrumented spinal fusion surgeries for osteoporotic spines. Neurologic injuries following long instrumentation are often serious and difficult to address with surgery alone. Conservative treatments should always be contemplated as an alternative method for patients with poor bone stock.
\end{abstract}

Keywords: osteoporotic spine, vertebral subluxation, junctional fracture, instrumented fusion, complication

\section{Introduction}

Medical care is becoming more complex and more costly, and many modern innovations of spinal instruments become popular and widespread in the health care system. ${ }^{1}$ Pedicle screw instrumented fixation that facilitates rigid fixation and higher fusion rate of the spines is widely accepted; however, instrumented fusion for osteoporotic spinal disorders is still a major challenge for spine surgeons. ${ }^{2}$ The use of long instrumentation for osteoporotic spines is controversial. Cement augmentation for the uppermost instrumented vertebra (UIV) and the adjacent unfused vertebral bodies had been reported. ${ }^{2,3}$ However, long instrumentations would transit the forces to the adjacent cephalad levels, leading to disc degeneration, failure of facet, and finally vertebral subluxation with neurologic complication. ${ }^{2}$

This study presents an unusual case of an 81-year-old Taiwanese woman who has been left with various spinal complications caused by repeated instrumented fusions for
Correspondence: Chiu-Liang Chen Department of Orthopedic Surgery, Changhua Christian Hospital, I 35

Nanxiao Street, Changhua City, Changhua County 500, Taiwan

Tel +88647 II 6 I28

Fax +88647 II6 129

Email IIIIII@cch.org.tw 
osteoporotic spine. There are only a few well-demonstrated reports with detailed radiographs and magnetic resonance images depicting diverse presentations of adjacent segment disease (ASD) including adjacent disc degeneration, posterior and anterior vertebral subluxation, end plate erosion, and adjacent compression fracture. Complications including progressive kyphosis, junctional fracture, and vertebral subluxation are challenging to address with surgery alone, and catastrophic neurologic injuries are usually permanent.

\section{Case presentation}

An 81-year-old Taiwanese woman underwent spinal decompression with posterior lumbar intervertebral fusion for L4-L5 degenerative spinal stenosis at a local hospital in Taiwan 10 years ago. Her past history included hypertension and diabetes with medical control for decades. Her bone mineral density examination showed osteoporosis.

The patient had been suffering from lower back pain with neurologic claudication for 6 months. She went to the same hospital, and the radiographs showed adjacent degenerative spinal stenosis with retrolisthesis of L2-L3 and L3-L4. On May 7, 2013, she underwent wide laminectomies of L2 to L4 with circumferential instrumented fusion from L5 to L1. The T12 and L1 vertebral bodies were augmented with cement. ${ }^{4}$ Postoperatively, her lower back pain and neurologic condition improved with good sagittal balance (Figure 1).

On July 1, 2013, she had severe back pain with kyphotic deformity. ${ }^{5}$ She denied any trauma since previous surgery. The radiographs showed $\mathrm{ASD}^{6,7}$ with posterior subluxation of T12 on L1 and proximal junctional angle ${ }^{5}$ of $52^{\circ}$ from T11 to L1. She had preserved muscle power of lower limbs with intact functions of micturition and defecation. On August 29, 2013, she underwent a revision surgery for the correction of T12 subluxation, cephalad extension of instrumented fusion to T9, and prophylactic T8 vertebroplasty. ${ }^{5,8}$ She wore a hyperextension brace postoperatively. The radiographs showed restored alignment of the spine (Figure 2).

On September 17, 2013, she complained of severe upper back pain with Grade B neurologic injury and compromised bladder sphincter function. The radiographs showed ASD with anterior subluxation of $\mathrm{T} 8$ and $36^{\circ}$ of proximal junctional kyphosis (T7-T9). The magnetic resonance image showed severe cord compression of T8-T9 level. The following surgery was performed on September 19, 2013,

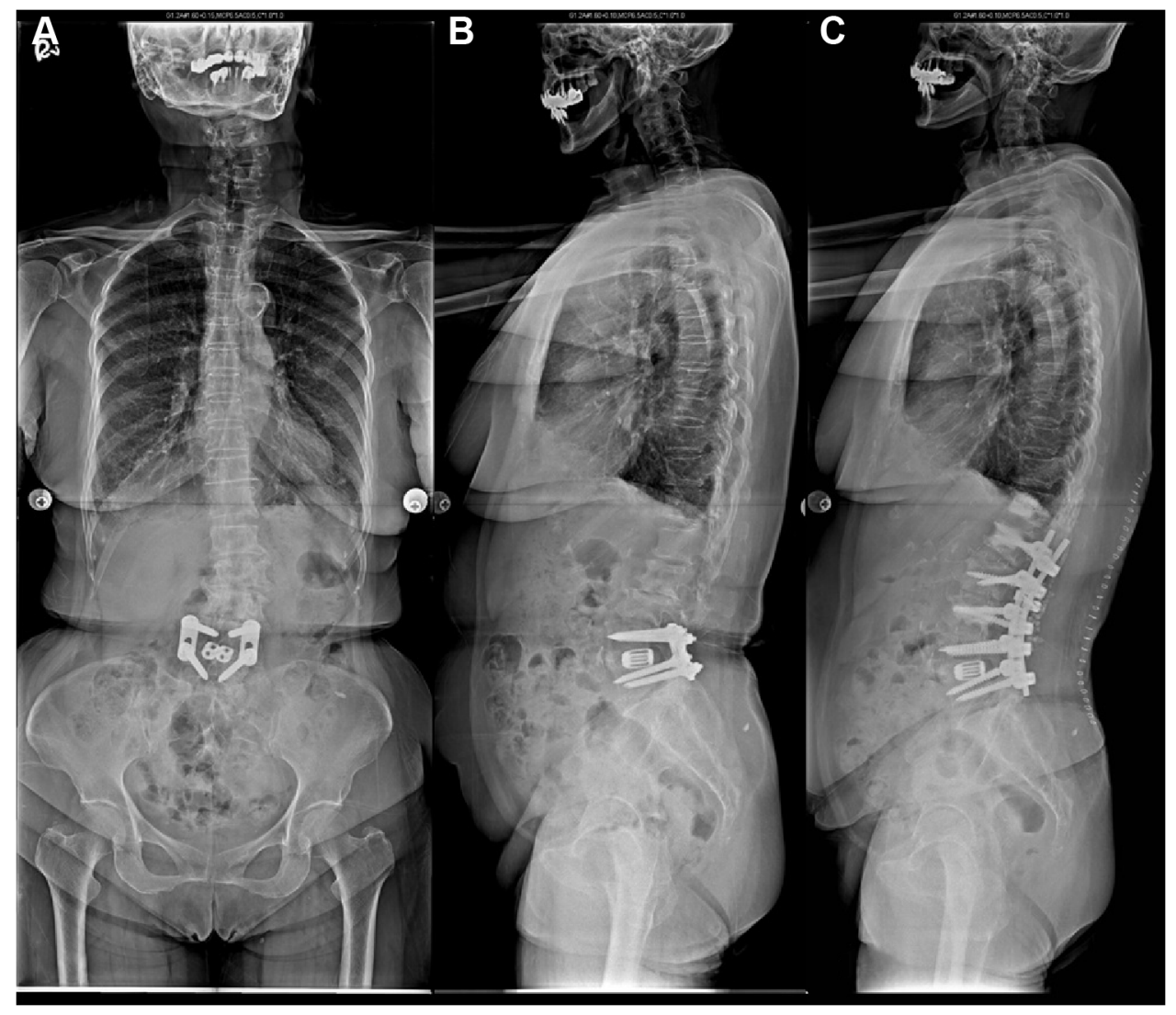

Figure I (A and B) Standing radiographs (anteroposterior and lateral view) showing degenerative disc change with retrolisthesis of L2-L3 and L3-L4; (C) the first immediately postoperative radiograph after instrumented fusion from LI to L5 with cement augmentation of TI 2 and LI. 


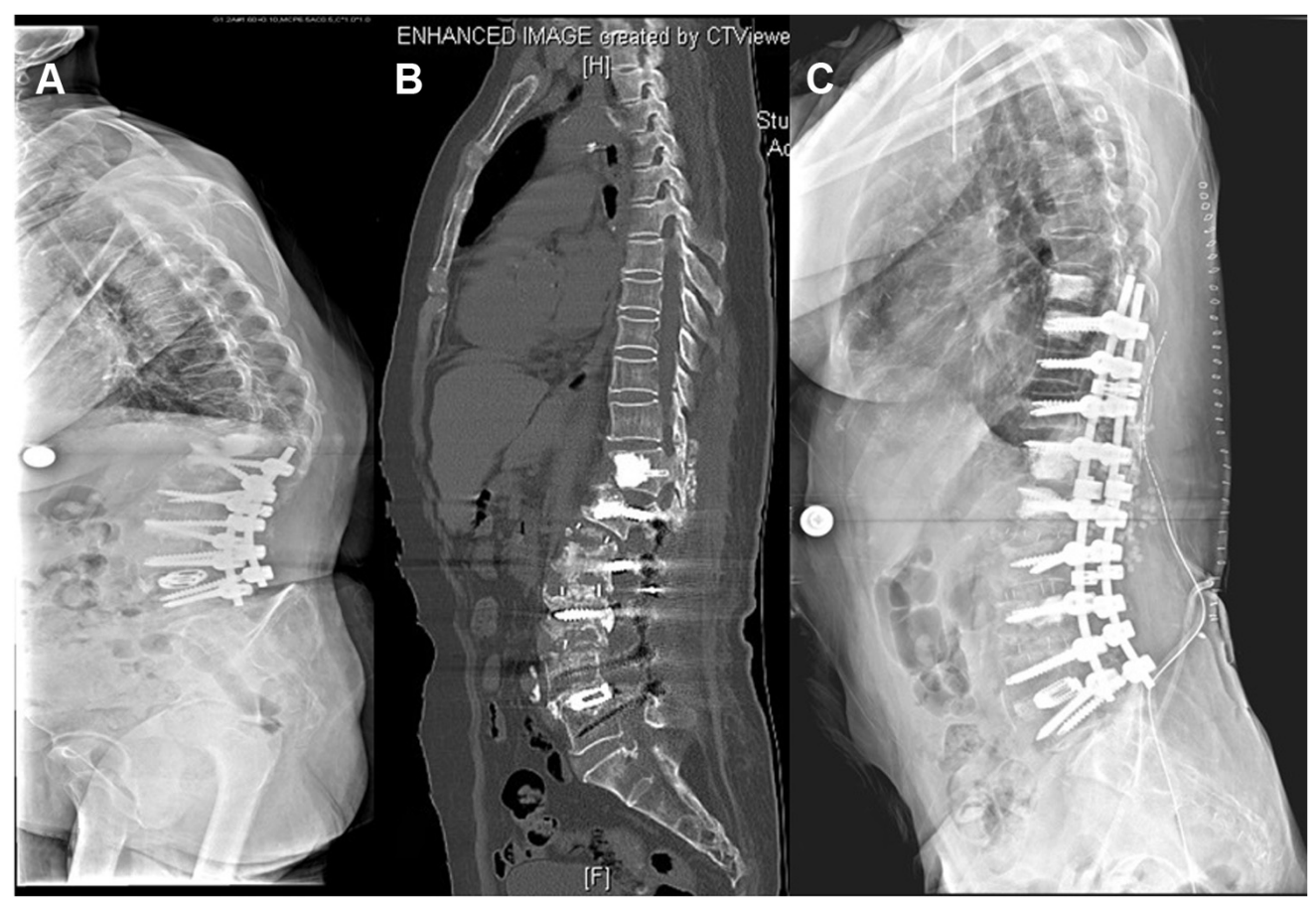

Figure 2 Seven weeks after the first surgery.

Notes: (A) Lateral view radiograph demonstrating subluxation of TI2 with proximal junctional angle of $52^{\circ}$ (TII-LI). (B) Computed tomography scan of spine showing $\mathrm{TI} 2$ subluxation. (C) The second immediately postoperative radiograph 15 weeks after the previous surgery with spinal instrumentation from T9 to L5 with cement augmentation of T8 and T9.

that is, extension of the spinal rods reached T2, which was augmented with cement. T1 did not have prophylactic vertebroplasty (Figure 3), and her neurologic grade and low micturition function were improving slowly.

On October 25, 2013, the patient suddenly developed acute pain over the neck area. She had an impairment of the micturition and defecation functions. The magnetic resonance image demonstrated T1 compression fracture involving the inferior end plate and $28^{\circ}$ segmental kyphosis with spinal cord compression (Figure 4). Because of her concomitant medical problems and the difficulty and controversy of subsequent surgery, she had conservative management with cervical thoracic orthosis support. She had been on rehabilitation therapy for 6 months after T1-T2 injury. Her neurologic function recovered very slowly with Grade $\mathrm{C}$ neurologic deficit 2 years after surgery.

\section{Discussion}

The pedicle screw fixation for spinal pathology has been widely used. ${ }^{9}$ Although pedicle screw constructs facilitate the rigid fixation and increase the fusion rate of arthrodesis, complications regarding increased stress on the unfused junctional segments is possible due to rigid fixation. $\mathrm{ASD}^{6,7,10}$ is a common complication following the spinal arthrodesis surgery. ${ }^{6}$ The biomechanical changes include increased intradiscal pressure, increased facet loading, and increased mobility after rigid fusion. ${ }^{6,11}$ The clinical risk factors consist of increasing patient age, osteoporosis, interbody fusion, disc degeneration, and facet instability. ${ }^{7,12,13}$ The length of fusion was a significant risk factor in the development of ASD in the lumbar spine. ${ }^{14}$

Osteoporosis may contribute to junctional vertebral fracture after instrumented fusion. ${ }^{2}$ Prophylactic vertebroplasty was recommended for augmenting the strength of the UIV and adjacent vertebra. ${ }^{8,15}$ Nevertheless, there are still debates over the protective function of prophylactic vertebroplasty. In a biomechanical cadaveric study, ${ }^{15}$ prophylactic vertebroplasty at the UIV and its supra-adjacent vertebra reduced the incidence of junctional fractures after long instrumented lumbar fusion. Ha et $\mathrm{al}^{5}$ suggested that vertebral augmentation may prevent junctional fracture of distal thoracic spines and vertebral subluxation of proximal thoracic spines, avoiding proximal junctional kyphosis and preserving sagittal balance. However, in another biomechanical study on cadaveric thoracic vertebrae, ${ }^{16}$ there was no statistically significant difference in failure loads between intact specimens and those that had undergone vertebroplasty. These studies have suggested that physicians should be careful when applying the concept of "prophylactic" vertebroplasty in patients at risk of fracture. 


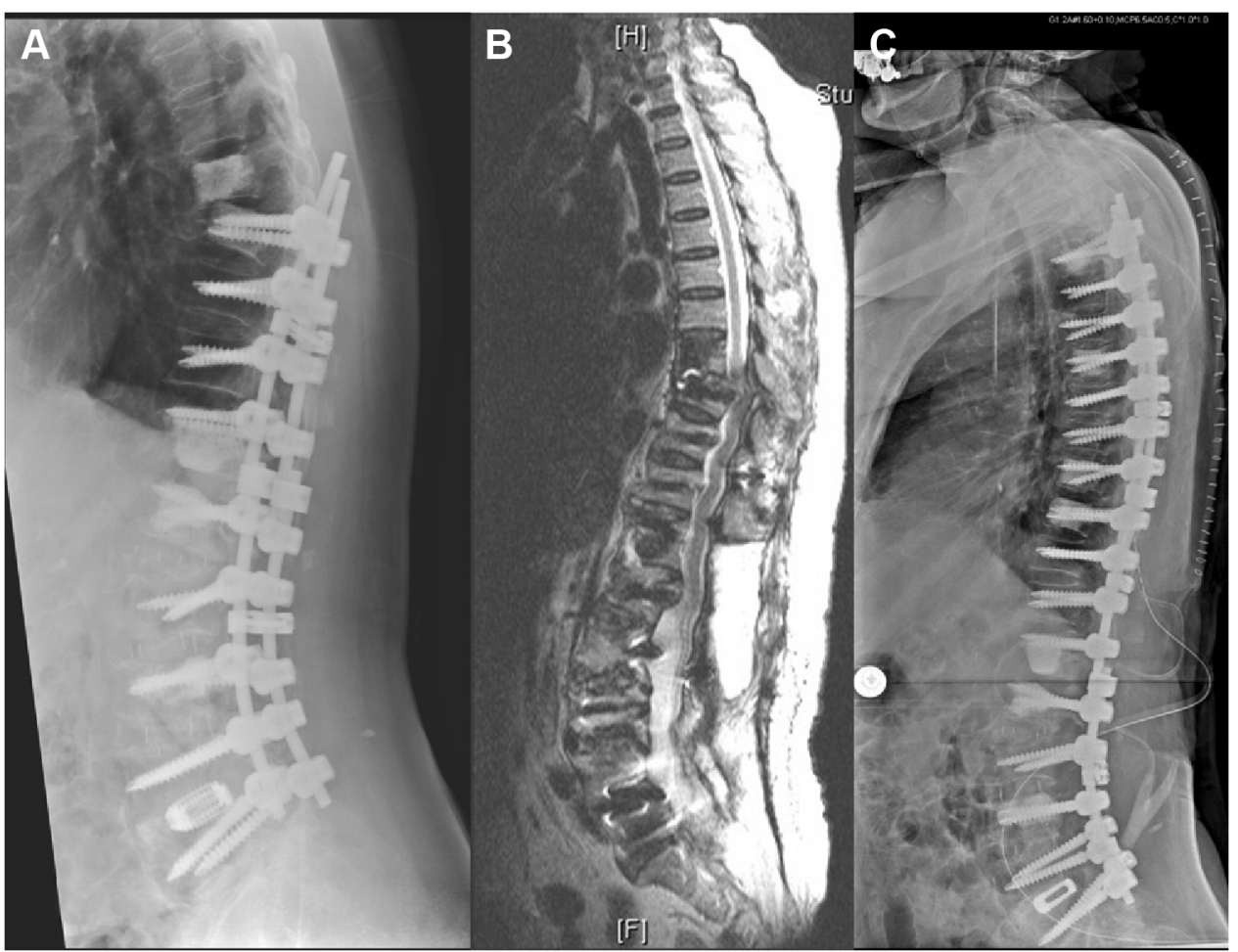

Figure 3 (A) Lateral radiograph demonstrating vertebral subluxation of T8 with proximal junctional angle of $36^{\circ}$ (T7-T9) 19 days after previous surgery; (B) magnetic resonance image showing T8 subluxation with severe cord compression; (C) the third immediately postoperative radiograph.

Note: The patient underwent extensive instrumented fusion from $\mathrm{T} 2$ to $\mathrm{L} 5$.

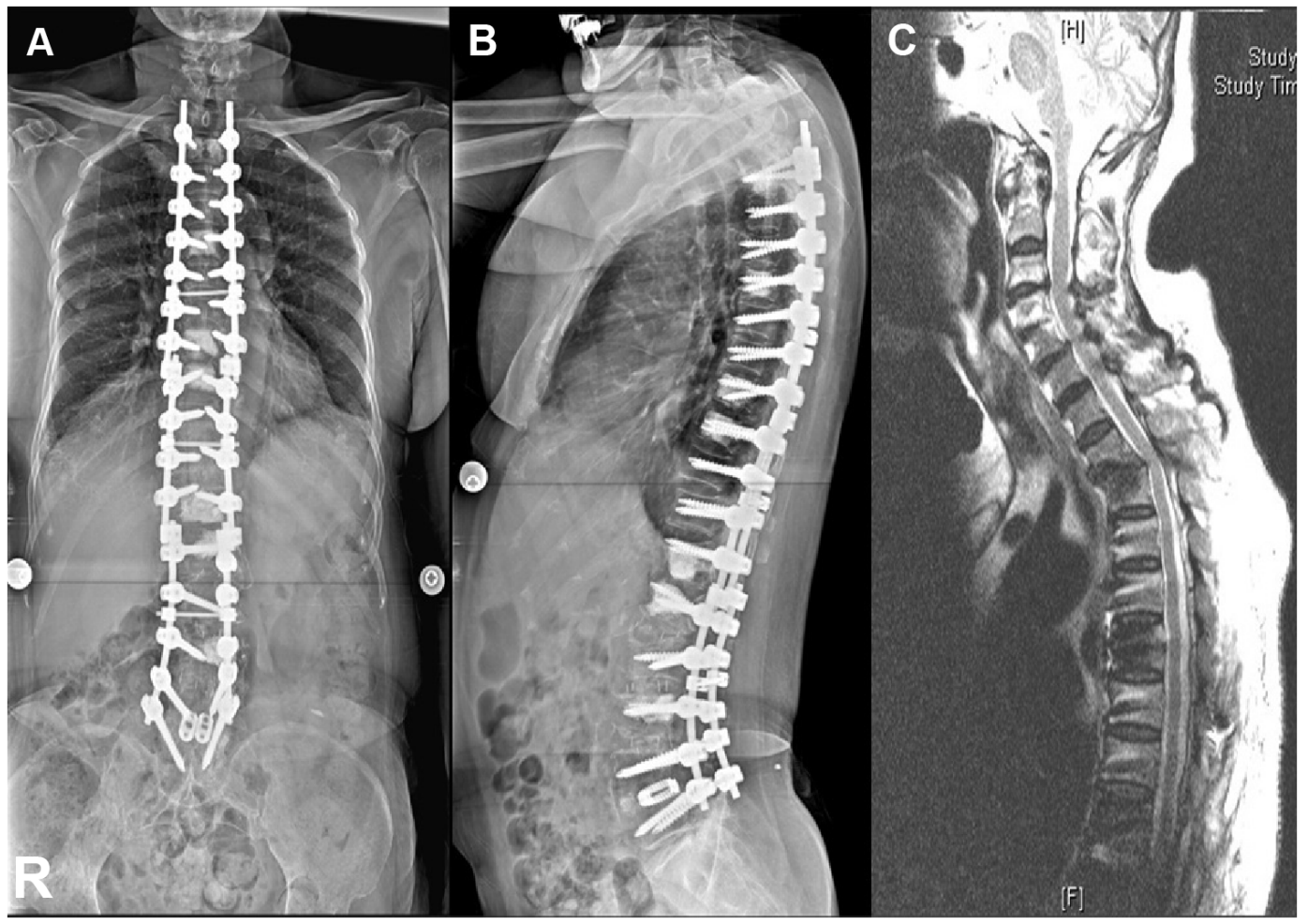

Figure 4 (A and B) The final whole spine radiographs; (C) magnetic resonance image showing fracture subluxation of TI with proximal junctional angle of $28^{\circ}$ (C7-T2) and severe cord compression 5 weeks after previous surgery. 
Some reports have documented ASD and postfusion instability at the adjacent segment secondary to rigid lumbar or lumbosacral fusion. ${ }^{6,10}$ However, there are only a few reports documenting repeated ASDs with various complications including adjacent disc degeneration, posterior and anterior vertebral subluxation, and adjacent osteoporotic fracture after repeated spinal surgeries from lower lumbar spine to upper thoracic spine in a single patient. ASD was considered a long-term potential complication of lumbar or lumbosacral fusion, ${ }^{6}$ but in our case, it happened sooner than expected.

Our patient developed two proximal junctional fracture types after repeated long instrumented fusion: adjacent vertebral subluxation and proximal junctional vertebral compression fracture with subluxation. ${ }^{5}$ The mechanism of junctional subluxation after long instrumented fusion might be caused by increased stress placed on the junction of the uppermost end plate and facets in UIV, leading to accelerated disc degeneration and failure of facets. Progressive kyphosis ${ }^{2}$ proximal to the instrumented fusion may transit the forces to the adjacent cephalad levels and cause disc degeneration. In addition, old age, severe osteoporosis, ${ }^{2}$ and global sagittal imbalance ${ }^{3,4}$ might be thought of as common features of proximal junctional fracture. Because the UIV and adjacent vertebral body were augmented with cement, the failure of the adjacent cemented vertebra did not develop; instead, increased facet loading and transition of the forces to the adjacent cephalad level might contribute to the subluxation of the unfused levels. ${ }^{17}$ The complications following subluxation of the uppermost vertebral body often lead to cord compression with serious neurologic compromise and are difficult to address with subsequent surgical intervention. ${ }^{2}$

This case report illustrated various complications with long fusions in osteoporotic individuals. This case is an extreme example and offers some points that should be noted. Even with meticulous preoperative planning, the surgical complication for osteoporotic spine with long instrumented fusion might occur. In many instances, wherever possible, operative treatment with long fusion should be avoided in these individuals. ${ }^{1}$ Bracing is always an option for treatment in these individuals.

The potential limitation of this report is that this is a single case presentation with low evidence level. However, it provides spine physicians an alternative thinking while dealing with such osteoporotic bone stock. The pros and cons of spine surgery should be discussed thoroughly, and conservative treatment should be considered in advance.

\section{Conclusion}

To the authors' knowledge, the case reported in this study is an extreme and rare example with various complications of ASD, junctional fracture, and vertebral subluxation following repeated elongations of the spinal instrumentations from lower $\mathrm{L}$ spine to upper $\mathrm{T}$ spine in an elderly patient with poor bone stock. This case highlighted the serious surgery complications due to long and repeated instrumented spine fusions for osteoporotic spine and emphasized the importance of conservative treatment as an alternative method for these elderly and osteoporotic patients.

\section{Acknowledgments}

The authors would like to acknowledge Shin-Lin Chiu for her help in the preparation of this paper Written informed consent was obtained from the patient for publication of this case report and any accompanying images.

\section{Author contributions}

Hsin-Yao Chen treated and clinically evaluated the patient, Chiu-Liang Chen drafted the manuscript and was the principal author of this case report, Wei-Liang Chen provided the readings of the radiographs and magnetic resonance images. All the authors contributed to manuscript revision and approved the final manuscript.

\section{Disclosure}

The authors report no conflicts of interests in this work.

\section{References}

1. Robertson JT. The rape of the spine. Surg Neurol. 1993;39(1):5-12.

2. DeWald CJ, Stanley T. Instrumentation-related complications of multilevel fusions for adult spinal deformity patients over age 65: surgical considerations and treatment options in patients with poor bone quality. Spine (Phila Pa 1976). 2006;31(19 Suppl):S144-S151.

3. Watanabe K, Lenke LG, Bridwell KH, Kim YJ, Koester L, Hensley M. Proximal junctional vertebral fracture in adults after spinal deformity surgery using pedicle screw constructs: analysis of morphological features. Spine (Phila Pa 1976). 2010;35(2):138-145.

4. Kim YJ, Bridwell KH, Lenke LG, Rhim S, Cheh G. Sagittal thoracic decompensation following long adult lumbar spinal instrumentation and fusion to L5 or S1: causes, prevalence, and risk factor analysis. Spine (Phila Pa 1976). 2006;31(20):2359-2366.

5. Ha Y, Maruo K, Racine L, et al. Proximal junctional kyphosis and clinical outcomes in adult spinal deformity surgery with fusion from the thoracic spine to the sacrum: a comparison of proximal and distal upper instrumented vertebrae. J Neurosurg Spine. 2013;19(3):360-369.

6. Park P, Garton HJ, Gala VC, Hoff JT, McGillicuddy JE. Adjacent segment disease after lumbar or lumbosacral fusion: review of the literature. Spine (Phila Pa 1976). 2004;29(17):1938-1944.

7. Rahm MD, Hall BB. Adjacent-segment degeneration after lumbar fusion with instrumentation: a retrospective study. J Spinal Disord. 1996;9(5) 392-400. 
8. Seo JY, Ha KY, Son IN, Chang DG, Kim YH. Percutaneous vertebroplasty for cephalad vertebral fractures after instrumented lumbar fusion. J Spinal Disord Tech. 2013;26(2):E58-E64.

9. Tsirikos AI, Subramanian AS. Posterior spinal arthrodesis for adolescent idiopathic scoliosis using pedicle screw instrumentation: does a bilateral or unilateral screw technique affect surgical outcome? J Bone Joint Surg Br. 2012;94(12):1670-1677.

10. Aota Y, Kumano K, Hirabayashi S. Postfusion instability at the adjacent segments after rigid pedicle screw fixation for degenerative lumbar spinal disorders. J Spinal Disord. 1995;8(6):464-473.

11. Bridwell KH, Lenke LG, Cho SK, et al. Proximal junctional kyphosis in primary adult deformity surgery: evaluation of 20 degrees as a critical angle. Neurosurgery. 2013;72(6):899-906.

12. Lee JC, Kim Y, Soh JW, Shin BJ. Risk factors of adjacent segment disease requiring surgery after lumbar spinal fusion: comparison of posterior lumbar interbody fusion and posterolateral fusion. Spine (Phila Pa 1976). 2014;39(5):E339-E345.

13. Lee JH, Kim JU, Jang JS, Lee SH. Analysis of the incidence and risk factors for the progression of proximal junctional kyphosis following surgical treatment for lumbar degenerative kyphosis: minimum 2-year follow-up. Br J Neurosurg. 2014;28(2):252-258.
14. Cheh G, Bridwell KH, Lenke LG, et al. Adjacent segment disease following lumbar/thoracolumbar fusion with pedicle screw instrumentation: a minimum 5-year follow-up. Spine (Phila Pa 1976). 2007;32(20):2253-2257.

15. Kebaish KM, Martin CT, O'Brien JR, LaMotta IE, Voros GD, Belkoff SM. Use of vertebroplasty to prevent proximal junctional fractures in adult deformity surgery: a biomechanical cadaveric study. Spine J. 2013;13(12):1897-1903.

16. Pneumaticos SG, Triantafyllopoulos GK, Evangelopoulos DS, Hipp JA, Heggeness MH. Effect of vertebroplasty on the compressive strength of vertebral bodies. Spine J. 2013;13(12):1921-1927.

17. Fernandez-Baillo N, Sanchez Marquez JM, Sanchez Perez-Grueso FJ, Garcia Fernandez A. Proximal junctional vertebral fracture-subluxation after adult spine deformity surgery. Does vertebral augmentation avoid this complication? A case report. Scoliosis. 2012;7(1):16.
Therapeutics and Clinical Risk Management

\section{Publish your work in this journal}

Therapeutics and Clinical Risk Management is an international, peerreviewed journal of clinical therapeutics and risk management, focusing on concise rapid reporting of clinical studies in all therapeutic areas, outcomes, safety, and programs for the effective, safe, and sustained use of medicines. This journal is indexed on PubMed Central, CAS,

\section{Dovepress}

EMBase, Scopus and the Elsevier Bibliographic databases. The manuscript management system is completely online and includes a very quick and fair peer-review system, which is all easy to use. Visit http://www.dovepress.com/testimonials.php to read real quotes from published authors. 